the algologist until the light fades. Then, on a clear, still night, each star sheds its 'road to the Isles' and the lights from the little sailing vessels mark the homeward journey of those islanders who have sold fruit and olive oil on the mainland quays during the day. Under such conditions can Cystoceira be studied in one of its most rewarding localities.

\section{LIIY NewToN}

\section{DISLOCATION THEORY}

Dislocations in Crystals

By W. T. Read, Jr. (International Series in Pure and Applied Physics.) Pp. xvii + 228. (London: McGraw-Hill Publishing Company, Ltd., 1953.) 36s.

7 HIS book has the well-defined object of setting down the strict logic of dislocation theory, and of deriving its consequences in some special physical situations where the dislocation structure is uniquely defined by the macroscopic conditions or by direct observation. The reader the author has in mind throughout is one who is willing to make an effort to teach himself; only a modest mathematical ability is required to follow the text and many of the numerous illustrative problems.

The first four chapters introduce the geometrical properties of single dislocations, their slip and climb movements, the concepts of stacking faults, partial dislocations and 'good' and 'bad' crystals. Chapter 5 gives the details of the forces on dislocations under uniform stress and is rather more mathematical. Chapters 6 and 7 are again geometrical and deal with dislocation multiplication mechanisms and the details of partial and extended dislocations in real lattices. Chapters 8 and 9 contain the mathematics of the stresses around dislocations and the forces of interaction between them, and conclude the first part of the book. The remaining five chapters deal with the application of the theory to two physical problemscrystal growth and the properties of grain boundaries. In the chapters dealing with the energy and mobility of boundaries a strongly critical approach is used, so that after a careful reading and study of the problems, the reader is left with an unusually clear picture of what is required by theory, and what is merely plausible.

The book is in no way concerned to introduce the reader to the whole scope of dislocation theory, and scarcely mentions such topics as the critical shear stress of single crystals, the yield-point phenomena or theories of work-hardening, recovery and polygonization. While the omission of these topics is in keeping with the policy of avoiding discussion of situations where the precise arrangement of the dislocations is unknown and important, it means that a reader wishing to master the interpretational side of dislocation theory must supplement Read's book with some other, such as Cottrell's "Dislocations and Plastic Flow in Crystals" (Oxford University Press).

There must, however, be many people concerned with plastic deformation of crystals, and having some familiarity with dislocations, who feel a need for a firmer logical and mathematical basis for their knowledge. This book, with its seventy or more problems and hundred references, should prove ideal for anyone prepared to read carefully and work constructively. Some of the problems make more demands on the reader's mathematics than does the main text, and a few sound rather like young research programmes. They all make the reader think.

The standard of production is the usual high one expected of the McGraw-Hill monographs. The text is lucid and illustrated by many well thought out diagrams. The paragraph headings in the detailed contents lists are likely to prove as useful for reference purposes as is the index, though the latter is pleasantly explicit. The limited public to whom the book is addressed should be well pleased with it; those who want a general account of physical hypotheses, however successful and widely accepted they may be, must look elsewhere. W. M. LOMER

\section{TEXT-BOOK OF APPLIED ELASTICITY}

Applied Elasticity

By Prof. Chi-Teh Wang. Pp. ix +357. (London: McGraw-Hill Publishing Company, Ltd., 1953.) 57s. $6 d$.

7 HIS book is written for "senior-graduate engineering students"; it is an advanced text-book rather than a mathematical treatise on elasticity. In it the author explains fundamental elasticity theory in fairly simple terms and then deals with several of the most useful analytical and numerical methods of solving problems.

The first two chapters are concise and deal with the analysis of stress and strain, all equations being given in component form in the manner of Timoshenko. Chapter 3 is concerned with stress-strain relations, and the theory is limited to that of isotropic solids; also included are short sections on strain energy, existence and uniqueness of solutions and St. Venant's principle. Plane-stress and planestrain problems, in both rectangular and polar co-ordinates, are dealt with in Chapter 4; this includes solutions for rotating disks and problems of thermal stress. Chapter 5 is devoted to torsion of prismatic bars, thin open sections, thin-walled tubes and circular shafts of variable diameter. An excellent chapter is devoted to finite difference approximations and the relaxation technique.

The principles of potential and complementary energy are introduced in Chapter 7 together with a discussion in terms of the variational calculus. Also included in this chapter are the Rayleigh-Ritz method, the so-called Galerkin method, the method of Biezeno and Koch, and finally the reciprocal theorem and Castigliano's theorems. This is followed by a chapter on solution by means of complex variables.

The remainder of the book is concerned with problems of "Advanced Strength of Materials". It comprises four chapters which deal respectively with the bending and compression of bars and elastic stability; numerical methods for finding critical loads ; the bending and buckling of thin plates; and thin shells.

When the purpose of the book is borne in mind:namely, the instruction of engineers-it is apparent that the author has selected the topics of his discussion with considerable skill. For little is included that is of interest only to the mathematician. The presentation is lucid, and problems are included for the reader who wishes to test his understanding of the theory.
R. E. D. BISHOP 